\title{
Renal Association Clinical Practice Guideline on the Assessment of the Potential Kidney Transplant Recipient
}

\author{
Dr Chris Dudley a and Dr Paul Harden ${ }^{\mathrm{b}}$ \\ ${ }^{a}$ Consultant Nephrologist, Richard Bright Renal Unit, Bristol \\ ${ }^{\mathrm{b}}$ Consultant Nephrologist, Oxford Kidney Unit, Oxford
}

\section{Key Words}

kidney transplant - potential transplant recipient $\cdot$ access to transplantation

\section{Introduction}

This clinical practice guideline addresses access to kidney transplantation together with the evaluation, selection and preparation of the potential kidney transplant recipient. Guidance on the medical management of the kidney transplant recipient is provided in another module of the Renal Association guidelines available at www.renal.org. Readers should refer to the joint British Society for Histocompatibility and Immunogenetics/ British Transplantation Society document for guidelines on the detection and characterisation of HLA antibodies in renal transplantation and to the NHS Blood and
Transplant/British Transplantation Society guidelines for consent for solid organ transplantation (www.bts.org. uk/standards-and-guidelines.htm) [1].

In this guideline Chronic Kidney Disease stage 5 (CKD 5) includes pre-dialysis and transplant patients with eGFR $<15 \mathrm{ml} / \mathrm{min} / 1.73 \mathrm{~m}^{2}$ as well as patients on dialysis i.e. CKD 5, CKD 5T and CKD 5D. This guideline is an updated version of the Renal Association guidance developed by the same lead co-authors published in 2007 and is based on a review of the literature between 2007 and 2010. Where evidence was available from RCTs and systematic reviews recommendations were based on these publications. Where there was a lack of evidence from high-quality studies, recommendations were based on the best available evidence taking in account the previous clinical practice guidelines on evaluation of the potential kidney transplant recipient from North America [2] and the European Renal Best Practice (ERBP) guidelines for renal transplantation [3].
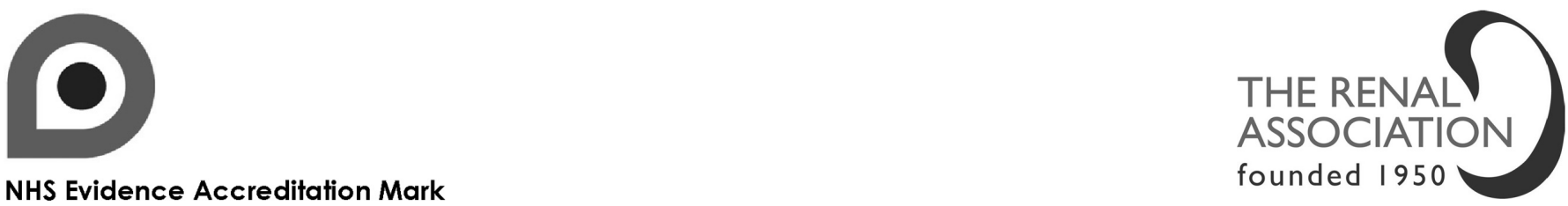

NHS Evidence Accreditation Mark

KARGER

Fax +4161306 1234

E-Mail karger@karger.ch

www.karger.com
C 2011 S. Karger AG, Basel

1160-2110/11/1185-000209\$38.00/0
Dr Chris Dudley and Dr Paul Harden

Email: chris.dudley@nbt.nhs.uk or paul.harden@orh.nhs.uk 
The recommendations in this update have been graded using the modified GRADE system to indicate both the strength of each recommendation (strong or weak) and level of evidence for the recommendation
(A-D) $[4,5]$. These guidelines on the assessment of the potential kidney transplant recipient have been endorsed by the British Transplantation Society.

\section{References}

1 www.bts.org.uk/standards-and-guidelines.htm

2 Kasiske BL, Cangro CB, Hariharan S et al. The evaluation of renal transplant candidates: clinical practice guidelines. Am J Transplant 2001;1(Suppl 2)

3 Berthoux F, Abramowicz D, Bradlet B et al. European best practice guidelines for renal transplantation (Part 1). Nephrol Dial Transplant 2000;15(Suppl 7)
4 Guyatt GH, Oxman AD, Vist GE et al. GRADE: an emerging consensus on rating quality of evidence and strength of recommendations. BMJ 2008;336:924-926

5 Uhlig K, MacLeod A, Craig J et al. Grading evidence and recommendations for clinical practice guidelines in nephrology. A position statement from Kidney Disease: Improving Global Outcomes (KDIGO). Kidney Int 2006;70:2058-2065 


\section{Summary of Clinical Practice Guideline on the Assessment of the Potential Kidney Transplant Recipient}

\section{Access to renal transplantation $(\mathrm{Tx})$ (Guidelines Tx 1.1-1.9)}

Guideline 1.1 - Tx : Access to renal transplantation

We recommend that kidney transplantation should be the renal replacement therapy of choice for the patient with chronic kidney disease stage 5 who is considered fit for major surgery and for chronic immunosuppression. All patients predicted to have an increased life expectancy post-transplantation should be assessed for transplantation. Placement on the transplant waiting list will be limited by individual co-morbidity and prognosis. (1A)

\section{Guideline 1.2 - Tx : Access to renal transplantation}

We recommend that living donor transplantation should be considered the treatment of choice for all patients suitable for renal transplantation when there is an appropriate donor. (1A)

Guideline 1.3 - Tx : Access to renal transplantation We recommend that patients with progressive deterioration in renal function suitable for transplantation should be placed on the national transplant list within six months of their anticipated dialysis start date. Pre-emptive transplantation should be the treatment of choice for all suitable patients whenever a living donor is available. (1A)

Guideline 1.4 - Tx : Access to renal transplantation

We recommend that there must be demonstrable equity of access to deceased donor kidney transplantation irrespective of gender, ethnicity or district of residence. (1A)

Guideline 1.5 - Tx : Access to renal transplantation

We recommend that age is not a contra-indication to transplantation but age related co-morbidity is an important limiting factor. (1B)

Guideline 1.6 - Tx : Access to renal transplantation

We recommend that all transplant units should have written criteria for acceptance on to the waiting list. The benefits and potential risks associated with transplantation should be fully explained both verbally and in writing. Potential transplant recipients should be informed of all

Guideline on the Assessment of the Potential Kidney Transplant Recipient donor options including living related and unrelated donation and the NHSBT/BTS guidelines for consent for solid organ donation should be followed. (1C)

Guideline 1.7 - Tx : Access to renal transplantation We recommend that all CKD 5 patients and CKD 4 patients with progressive disease should have their suitability for transplantation assessed annually and that appropriate patients should be referred to a transplant centre. When transplantation is considered inappropriate the reason(s) should be documented. All patients on the transplant list should be assessed annually to determine whether transplantation remains appropriate. Patients should be placed on, or removed from the waiting list only after discussion and agreement with the nephrologist, transplant surgeon and the patients themselves according to local practice. (1C)

Guideline 1.8 - Tx : Access to renal transplantation

We recommend that the care of the renal transplant recipient is best undertaken by a multi-disciplinary team. (1C)

Guideline 1.9 - Tx : Access to renal transplantation

We recommend that simultaneous kidney-pancreas transplantation or living donor renal transplantation is the treatment of choice for patients with Type 1 diabetes mellitus who are suitable for renal transplantation. (1B)

2. Evaluation, selection and preparation of the potential transplant recipient ( $\mathrm{Tx}$ ) (Guidelines $\mathrm{Tx}$ 2.1-2.9)

\section{Guideline 2.1 - Tx : Pre-transplant assessment}

We recommend that the object of pre-transplant assessment is: (a) to ensure transplantation is technically possible; (b) to ensure the recipient's chances of survival are not compromised by transplantation; (c) to ensure that graft survival is not limited by premature death (maximum benefit obtained from a limited resource); (d) to ensure pre-existing conditions are not exacerbated by transplantation; (e) to identify measures to be taken to minimise peri- and post-operative complications; (f) to inform patients of the likely risks and benefits of transplantation. (1C)

\section{Guideline 2.2 - Tx : Pre-transplant cardiac} assessment

We suggest that there is no compelling evidence that pre-transplantation screening tests for coronary artery

Nephron Clin Pract 2011;118(suppl 1):c209-c224 
disease in asymptomatic patients with established renal failure is effective in preventing future cardiac events or reducing mortality after transplantation. Until better evidence emerges, screening tests may be best used to identify high-risk patients for exclusion from the transplant waiting list. (2C)

\section{Guideline 2.3 - Tx : Preparation of the renal transplant recipient}

We suggest that the use of pre-operative beta-blockers may be considered in patients at high cardiovascular risk undergoing renal transplantation but should be introduced at least 1 month before transplantation. Beta-blockers should not be discontinued abruptly peri-operatively. Low dose aspirin and clopidogrel therapy are not contraindications to transplantation. (2C)

\section{Guideline 2.4 - Tx : Preparation of the renal transplant recipient}

We recommend that patients should be strongly encouraged to stop smoking before and after transplantation. Formal smoking cessation programmes should be offered and accessed in primary care. (1A)

\section{Guideline 2.5 - Tx : Preparation of the renal transplant recipient}

We suggest that obese patients (BMI $>30 \mathrm{~kg} / \mathrm{m}^{2}$ ) present technical difficulties and are at increased risk of peri-operative complications. They should be screened rigorously for cardiovascular disease and each case considered individually. Although obesity is not an absolute contra-indication to transplantation, individuals with a BMI $>40 \mathrm{~kg} / \mathrm{m}^{2}$ are less likely to benefit. (2B)

\section{Guideline 2.6 - Tx : Preparation of the renal transplant recipient}

We recommend that all potential transplant recipients should be tested for prior exposure to viral infections including: cytomegalovirus (CMV), Epstein-Barr virus (EBV), varicella zoster virus (VZV), hepatitis B and C and human immunodeficiency virus (HIV). Immunisation should be offered to all hepatitis B (if not already immunised) and VZ virus antibody negative patients before transplantation. Patients otherwise suitable for renal transplantation with evidence of chronic hepatitis B and/or C or HIV infection should be managed according to British Transplantation Society and European Best Practice Guidelines prior to transplantation. (1A)
Guideline $2.7-T x$ : Evaluation and selection of the renal transplant recipient

We recommend that renal transplantation should only be considered in potential recipients with previous malignancy (excluding non-melanoma skin cancer) if there is no evidence of persistent cancer. It is recommended that the waiting time between successful tumour treatment/remission and transplantation be at least 2 years. For certain malignancies the waiting time may need to be extended to more than 5 years. The Israel Penn International Transplant Tumour Registry should be consulted for tumour specific advice (Www. ipittr.uc.edu/Home.cfm). (1A)

\section{Guideline 2.8 - Tx : Evaluation and selection of the renal transplant recipient}

We recommend that patients who are at risk of developing recurrence of original renal disease should be managed according to the European Best Practice Guidelines (EBPG). (not graded)

Guideline 2.9-Tx : Screening investigations in the renal transplant recipient

We suggest that there is no evidence that asymptomatic potential transplant recipients require screening for diverticular disease, peptic ulceration or gall bladder stones. (2C)

\section{Summary of audit measures in assessment for renal transplantation}

1. The proportion of patients with and without diabetes mellitus $<65$ years old with CKD stage 5 listed for transplantation.

2. The proportion of transplant patients who receive a living donor transplant.

3. The time to placement on the UK Transplant national transplant list in relation to start date of dialysis.

4. The proportion of living donor transplant recipients transplanted before starting dialysis.

5. A comparison between renal units of the proportion of dialysis patients placed on the national transplant list corrected for differences in identified unit and patient specific variables including co-morbidity.

6. The proportion of CKD stage 5 patients with a transplant status recorded. 
7. The proportion of CKD stage 5 dialysis patients with Type 1 diabetes mellitus listed for simultaneous kidney-pancreas transplantation.

8. The proportion of patients who smoke (or have given up within the last year)

(a) while listed for transplantation

(b) one year after renal transplantation.

9. The number of patients with $\mathrm{BMI}>40 \mathrm{~kg} / \mathrm{m}^{2}$ who are on the transplant waiting list and the reason for their inclusion.
10. The proportion of patients on the transplant waiting list whose viral status is known for CMV, EBV, VZV, hepatitis B and C and HIV.

11. The proportion of VZV and HBc antibody negative patients on the transplant waiting list who have been immunised against these viruses. 


\section{Rationale for clinical practice guidelines for assessment of the renal transplant recipient}

\section{Access to renal transplantation $(\mathrm{Tx})$ (Guidelines Tx 1.1-1.9)}

Guideline 1.1 - Tx : Access to renal transplantation

We recommend that kidney transplantation should be the renal replacement therapy of choice for the patient with chronic kidney disease stage 5 who is considered fit for major surgery and for chronic immunosuppression. All patients predicted to have an increased life expectancy post-transplantation should be assessed for transplantation. Placement on the transplant waiting list will be limited by individual co-morbidity and prognosis. (1A)

\section{Audit measure}

The proportion of patients with and without diabetes mellitus $<65$ years old with CKD stage 5 listed for transplantation.

\section{Rationale}

Patients' survival following renal transplantation is better compared to age-matched individuals remaining on the transplant waiting list [1]. In a series of 46,164 patients on the transplant waiting list in the USA between 1991-1997, mortality was 68\% lower for transplant recipients than for those remaining on the transplant waiting list for $>3$ years follow-up [1]. This resulted in a mean increase in projected survival of 10 years, maximised in the 20-39 year old age group, who were predicted to live 17 years longer than their counterparts remaining on the transplant waiting list. The increased survival benefit was seen in both sexes and was even more marked in diabetics. This analysis was confined to those patients admitted to the waiting list using the criteria for fitness for transplantation in use at the time of the study in the USA, and therefore cannot safely be extrapolated to higher risk potential transplant candidates. Although a smaller study from Scotland replicated these findings, a similar more recent analysis from the UK showed that patients over the age of 65 years did not experience any survival advantage compared with matched patients who were listed but not transplanted $[2,3]$.

Guideline 1.2 - Tx : Access to renal transplantation

We recommend that living donor transplantation should be considered the treatment of choice for all patients suitable for renal transplantation when there is an appropriate donor. (1A)

\section{Audit measure}

The proportion of transplant patients who receive a living donor transplant

\section{Rationale}

The demand for renal transplantation has consistently and increasingly outstripped the number of available deceased donor organs for the last 20 years. In 2005 this shortfall had increased to over 6,000 patients [4]. Donation of a kidney from a living donor increased by $12 \%$ in 2008/9 in the UK and is the most realistic option to expand organ donation [4, 5]. Living donor kidney transplantation provides most patients with the best chance of long-term rehabilitation and it also facilitates access to deceased donor transplantation for those without a living donor. The opportunity for planned transplantation before dialysis is required is an attractive option for patients and evidence suggests that there is improved graft survival of transplants performed pre-emptively [6]. During the last 5 years there has been substantial increase in living donor kidney transplantation in the UK which now accounts for $38 \%$ of the total kidney transplant programme (living donor kidney transplantation rate has increased from 9.2 per million population pmp in 2005 to $17.2 \mathrm{pmp}$ in 2010 in the UK [4]). Living kidney donation also enables scheduling of transplantation at a time when the recipient is in optimal medical and psychological condition and may be the only option in high-risk recipients.

\section{Guideline 1.3 - Tx : Access to renal transplantation}

We recommend that patients with progressive deterioration in renal function suitable for transplantation should be placed on the national transplant list within six months of their anticipated dialysis start date. Pre-emptive transplantation should be the treatment of choice for all suitable patients whenever a living donor is available. (1A)

\section{Audit measures}

1. The time to placement on the national transplant list in relation to the start date of dialysis.

2. The proportion of living donor transplant recipients transplanted before starting dialysis.

\section{Rationale}

In a series of 25,758 recipients of first deceased donor kidney transplants in the USA between 1995-1998, 
pre-emptive transplantation was associated with a $25 \%$ reduction in graft failure and $16 \%$ reduction in mortality compared to recipients receiving a transplant when already established on dialysis [7]. In 13,078 pre-emptive living related transplant recipients from the same series, there was a $31 \%$ reduction in mortality and a $27 \%$ reduction in graft failure [7]. Transplant survival is negatively influenced by the duration of dialysis before transplantation, with a 5 year allograft survival of approximately $85 \%$ in pre-emptive transplantation compared with $75 \%$ in those receiving dialysis for 3-4 years before transplantation [6]. Patients with advanced CKD should receive a renal transplant as soon as possible to optimise clinical outcomes. Under Standard Two of The National Service Framework for Renal Services (Part One), a marker of good practice is the placement of patients on the national transplant list within six months of their anticipated dialysis start date if clinically appropriate [8]. Early pre-emptive transplantation with a higher eGFR (=15) does not improve graft survival after kidney transplantation, compared to pre-emptive transplantation with a lower eGFR $(<10)$ [9].

Within the UK there is evidence of significant differences between renal units in the time taken to register patients on the national transplant list that cannot be explained by differences in patient characteristics [10].

\section{Guideline 1.4 - Tx : Access to renal transplantation}

We recommend that there must be demonstrable equity of access to deceased donor kidney transplantation irrespective of gender, ethnicity or place of residence. (1A)

\section{Audit measure}

A comparison between renal units of the proportion of dialysis patients placed on the national transplant list corrected for differences in identified unit and patient specific variables including co-morbidity

\section{Rationale}

Renal transplantation remains the most successful and cost-effective treatment for suitable patients with established renal failure. Not all patients receiving dialysis are suitable for kidney transplantation and there is evidence that selection criteria vary widely throughout the UK [11-13]. At the beginning of 2009, 38\% of all patients treated with dialysis were active (or suspended) on the national transplant waiting list. NHS Blood and Transplant coordinates deceased-donor kidney allocation according to a nationally agreed algorithm. In
2004, the UK Transplant Kidney and Pancreas Advisory Group commissioned an Equity of Access Task Force to identify factors that may lead to inequity of access to renal transplant waiting lists, to recommend methods through which unjustified inequity may be removed and to determine methods through which this could be identified. The report from this Task Force contributed in part to the development and implementation of a new national renal allocation algorithm in 2006 and modified further in 2008. A key recommendation from this group was the above audit measure [14]. Recent data from the UK suggests that while gender had no effect on the probability of placement on the national transplant waiting list, ethnic minorities were less likely to be listed within 2 years of start of dialysis compared to white patients, although this difference could be explained by differences in patient characteristics and social deprivation $[10,15]$. However, patients cared for in non-transplanting renal units were less likely to be registered for transplantation compared to patients cared for in transplanting renal centres [10]. Furthermore, there were significant differences between renal units in the probability of being activated on the waiting list within 2 years of starting dialysis that could not be explained by case-mix (age, ethnicity and primary renal diagnosis) [10].

\section{Guideline 1.5 - Tx : Access to renal transplantation}

We recommend that age is not a contra-indication to transplantation but age related co-morbidity is an important limiting factor. (1B)

\section{Rationale}

There is an imbalance between the availability of donor organs and demand for renal transplantation in the UK [16]. The shortfall of deceased donor organs has resulted in the national allocation scheme - coordinated by NHS Blood and Transplant. New allocation criteria were introduced in a phased manner in 2006 and in 2008 to minimise racial and geographical inequities [17]. Population studies have shown reduced rates of access to transplantation for African Americans in the USA and British Asians in the UK $[7,18]$ although recent data from the UK suggests that after correction for patient characteristics and social deprivation, no such reduced access exists [15].

There is evidence that selection criteria for placement on the transplant waiting list vary significantly throughout the UK [10]. It is important that centres managing patients with stage 4 and 5 CKD follow standardised 
procedures for evaluation of suitability for transplantation. Each transplant centre should have written protocols for transplant assessment consistent with European and North American Guidelines [10, 19]. Improved life expectancy of first deceased donor transplant recipients over patients remaining on the waiting list is seen in all age groups in a US study [20]. Transplant recipients between ages $60-74$ had a $61 \%$ reduction in mortality and increased predicted survival of 4.3 years over matched patients remaining on the transplant waiting list [20]. In contrast, in a more recent UK analysis, patients over the age of 65 years did not experience any survival advantage compared with matched patients who were listed but not transplanted over 5 years of follow-up [1]. Quality of life, however, may be improved. Potential recipients aged 50 or greater should have a careful evaluation of cardiovascular co-morbidity.

Guideline 1.6 - Tx : Access to renal transplantation

We recommend that all transplant units should have written criteria for acceptance on to the waiting list. The benefits and potential risks associated with transplantation should be fully explained both verbally and in writing. Potential transplant recipients should be informed of all donor options including living related and unrelated donation and the NHSBT/BTS guidelines for consent for solid organ donation should be followed. (1C)

\section{Rationale}

It is important that all potential transplant recipients should receive comprehensive information on the risks of transplantation, the results compared with dialysis and the options in terms of different types of donor. All patients should receive education about all forms of living donor transplantation including paired/pooled exchange and antibody incompatible transplantation. Recommendations made in the NHSBT/BTS guidelines for consent for solid organ donation should be adhered to $[21]$.

Guideline 1.7 - Tx : Access to renal transplantation We recommend that all CKD 5 patients and CKD 4 patients with progressive disease should have their suitability for transplantation assessed annually and that appropriate patients should be referred to a transplant centre. When transplantation is considered inappropriate the reason(s) should be documented. All patients on the transplant list should be assessed annually to determine whether transplantation remains appropriate.
Patients should be placed on, or removed from the waiting list only after discussion and agreement with the nephrologist, transplant surgeon and the patients themselves according to local practice. (1C)

\section{Audit measure}

The proportion of CKD stage 5 patients with a transplant status recorded

\section{Rationale}

Clinical practice differs from centre to centre with regard to selection for transplantation [10]. It is important to review all patients with stage 4 and 5 CKD as potential transplant recipients according to local written protocols. Limitation of access to transplantation by age, gender, social and ethnic background is unacceptable and must be prevented by a standardised assessment mechanism.

The median waiting time to transplantation in the UK for adult patients registered on the kidney transplant waiting list during 2001-2004 was 902 days [22]. CKD is associated with accelerated cardiovascular disease [23] requiring regular review of patients on the waiting list to detect emerging co-morbidities which may compromise the outcomes of renal transplantation. Surveillance for cardiovascular disease may need to be more frequent in high risk groups such as individuals with previous cardiac intervention or re-transplantation.

\section{Guideline 1.8 - Tx : Access to renal transplantation}

We recommend that the care of the renal transplant recipient is best undertaken by a multi-disciplinary team. The supporting role of transplant nurse specialists in living donor/recipient preparation and recipient care is highly desirable. (1C)

\section{Rationale}

Optimal early and maintenance care post-transplantation requires close co-operation between health care professionals of different disciplines including H\&I scientist, transplant surgeon, nephrologist, anaesthetist, radiologist, histopathologist, renal pharmacist and specialist in infectious disease. Nurse practitioners are increasingly providing a pivotal role in transplant assessment and subsequent co-ordination of maintenance transplant recipients $[24,25]$.

Guideline 1.9 - Tx : Access to renal transplantation

We recommend that simultaneous kidney-pancreas transplantation or living donor renal transplantation is 
the treatment of choice for patients with Type 1 diabetes mellitus who are suitable for renal transplantation. (1B)

\section{Audit measure}

The proportion of CKD stage 5 dialysis patients with Type 1 diabetes mellitus listed for simultaneous kidneypancreas transplantation

\section{Rationale}

In diabetic patients, kidney transplantation leads to a marked improvement in patient and graft survival compared with continued dialysis [1]. A number of studies have demonstrated improved survival for diabetic recipients of simultaneous pancreas-kidney (SPK) transplants compared with deceased donor kidney alone transplants (KA) [26, 27]. Furthermore, US Registry data suggest that diabetic recipients of deceased donor SPK and living donor KA transplants have similar 5 year mortality risks that are significantly better than that of diabetic recipients of deceased donor KA transplants [28]. However, a recent analysis reports enhanced graft survival rates in living donor KA transplantation compared to SPK [29]. It is recommended that all type 1 diabetics with advanced CKD suitable for transplantation should be considered for living donor transplantation if available, particularly as the waiting time for SPK is increasing. All these studies are potentially flawed by selection bias and re-analysis of the UNOS database after correction for differences in donor and recipient risk factors gives similar shortterm patient and graft survival between recipients of SPK and KA transplants [30]. However, some studies show that recipients of SPK transplants report better physical health and quality of life in areas that are diabetes specific compared with recipients of KA transplants [31, 32], Furthermore, there is accumulating, but as yet inconclusive, evidence that pancreas transplantation may halt and potentially improve some of the long-term complications of diabetes mellitus including retinopathy [33], nephropathy [34] and neuropathy [35]. 


\section{References}

$\checkmark 1$ Wolfe RA, Ashby VB, Milford EL et al. Comparison of mortality in all patients on dialysis, patients on dialysis awaiting transplantation and recipients of a first cadaveric transplant. New Eng J Med 1999; 341:1725-1730

2 Oniscu GC, Brown H, Forsythe JLR. Impact of cadaveric renal transplantation on survival in patients listed for transplantation. J Am Soc Nephrol 2005;16:1859-1865

$\checkmark 3$ Ansell D, O’Neill JO, Johnson R et al. Transplantation of older patients does not improve survival compared with those wait listed. Analysis of 9,700 wait listed patients in the UK. Transplantation 2008;86(2S):314

4 http://www.uktransplant.org.uk/ukt/statistics/transplant_activity_report/ current_activity_reports/ukt/activity_report_2009_10.pdf

$\checkmark 5$ Ingelfinger JR. Risks and benefits to the living donor. N Engl J Med 2005;353:447-449

-6 Meier-Kriesche HU, Kaplan B. Waiting time on dialysis as the strongest modifiable risk factor for renal transplant outcomes. Transplantation 2002;74(10):1377-1381

7 Kasiske BL, Snyder JJ, Matas MD at al. Pre-emptive kidney transplantation: The advantage and the advantaged. J Am Soc Nephrol 2002;13: 1358-1364

8 The National Service Framework for Renal Services (Part One: Dialysis and Transplantation), Department of Health, January 2005

$\checkmark 9$ Akkina SK, Connaire JJ, Snyder JJ et al. Earlier is not necessarily better in preemptive kidney transplantation. Am J Transplant 2008;8:2071-2076

10 Ravanan R, Udayaraj U, Ansell D et al. Variation between centres in access to renal transplantation in the UK; longitudinal cohort study. BMJ 2010;341:c3451

11 McMillan MA, Briggs JD. Survey of patient selection for cadaveric transplantation in the United Kingdom. Nephrol Dial Transplant 1995; 10:855-858

12 Oniscu GC, Schalkwijk AA, Johnson RJ et al. Equity of access to renal transplant waiting list and renal transplantation in Scotland: cohort study. BMJ. 2003;327(7426):1261

13 Dudley C, Johnson RJ, Thomas, et al. Joint Analyses with UK Transplant in England and Wales UK Renal Registry Report 2005;5:69-85

14 UKT KPAG Equity of Access Task Force. Overview Report 2006 RTSM (06) 2

15 Udayaraj U, Ben-Shlomo Y, Roderick P et al. Social deprivation, ethnicity and access to the deceased donor kidney transplant waiting list in England and Wales. Transplantation 2010;90:279-285

16 www.uktransplant.org.uk/ukt/statistics/statistics.jsp

17 www.uktransplant.org.uk/ukt/about_transplants/organ_allocation/ kidney_(renal)/kidney_(renal).jsp

18 Jeffrey RF, Woodrow G, Mahler J et al. Indo-Asian experience of renal transplantation in Yorkshire: results of a 10-year survey. Transplantation 2002 May 27;73(10):1652-1657
19 Kasiske BL, Cangro CB, Hariharan S et al. The evaluation of renal transplant candidates: clinical practice guidelines. Am J Transpl 2001; 1(Suppl 2)

20 Berthoux F, Abramowicz D, Bradlet B et al. European best practice guidelines for renal transplantation (Part 1). Nephrol Dial Transpl 2000;15(Suppl 7)

21 http://www.bts.org.uk/transplantation/standards-and-guidelines/

22 http://www.uktransplant.org.uk/ukt/statistics/centre-specific_reports/ centre-specific_reports.jsp

23 Levin A, Foley RN. Cardiovascular disease in chronic renal insufficiency. Am J Kidney Dis 2000;36:S24-S30

24 Burnapp L. Living donor transplantation: Impact of patient focused care on donor outcomes. EDTNA ERCA 1998:24(2):11

25 Short CD, Russell S, Valentine A. Clinical audit and long-term evaluation of renal transplant recipients. Transplantation 2001;72:S94-S98

26 Smets YF, Waeterndorp RG, van der Pijl JW et al. Effect of simultaneous pancreas-kidney transplantation on mortality of patients with type-1 diabetes mellitus and end-stage renal failure. Lancet 1999;353:1915-1919

27 Sollinger HW, Odorico JS, Knechtle SJ et al. Experience with 500 simultaneous pancreas-kidney transplants Ann Surg 1998;228:284-296

28 Ojo AO, Meier-Kriesche HU, Hanson JA et al. The impact of simultaneous pancreas-kidney transplantation on long-term patient survival. Transplantation 2001;71(1):82-90

29 Young BY, Gill J, Huang E et al. Living donor kidney versus simultaneous pancreas-kidney transplant in type 1 diabetics. Clin J Am Soc Nephrol 2009;4:700-702

30 Bunnapradist S, Cho YW, Cecka JM et al. Kidney allograft and patient survival in type I diabetic recipients of cadaveric kidney alone versus simultaneous pancreas kidney transplants: a multivariate analysis of the UNOS database. J Am Soc Nephrol 2003;14(1):208-213

-31 Gross CR, Limwattananon C, Matthees B et al. Impact of transplantation on quality of life in patients with diabetes and renal dysfunction. Transplantation 2000;70(12):1736-1746

-32 Adang EM, Engel GL, van Hooff JP et al. Comparison before and after transplantation of pancreas-kidney and pancreas-kidney with loss of pancreas - a prospective controlled quality of life study. Transplantation 1996;62(6):754-758

33 Chow VC, Pai RP, Chapman JR et al. Diabetic retinopathy after combined kidney-pancreas transplantation. Clin Transplant 1999;13: 356-362

34 Fioretto P, Steffes MW, Sutherland DE et al. Reversal of lesions of diabetic nephropathy after pancreas transplantation. New Eng J Med 1998;339:69-75

35 Cashion AK, Hathaway DK, Milstead EJ et al. Changes in patterns of 24-hr heart rate variability after kidney and kidney-pancreas transplant. Transplantation 1999;68:1846-1850 


\section{Evaluation, selection and preparation of the potential transplant recipient ( $\mathrm{Tx}$ ) (Guidelines $\mathrm{Tx}$ 2.1-2.9)}

\section{Guideline 2.1 - Tx : Pre-transplant assessment}

We recommend that the object of pre-transplant assessment is: (a) to ensure transplantation is technically possible; (b) to ensure the recipient's chances of survival are not compromised by transplantation; (c) to ensure that graft survival is not limited by premature death (maximum benefit obtained from a limited resource); (d) to ensure pre-existing conditions are not exacerbated by transplantation; (e) to identify measures to be taken to minimise peri- and post-operative complications; (f) to inform patients of likely risks and benefits of transplantation. (1C)

\section{Rationale}

The main goal of renal transplantation is to improve the life expectancy and quality of life of patients with established renal failure. It follows, therefore, that patients who are predicted to have their lives shortened by transplantation or to experience a worsening quality of life should be excluded from the transplant waiting list. It is acknowledged that making such predictions is often difficult and imprecise and that the quality of data to support rational decision making is generally inadequate. There is evidence that selection criteria vary widely throughout the UK as reflected by variation in the proportion of patients who are on the transplant waiting list at different renal units [1]. In July 2003, the British Transplantation Society and Renal Association published waiting list criteria for potential renal transplant recipients based, with some minor modifications, on the European Best Practice Guidelines (2000) [2]. The major difference was in the exclusion of patients with a predicted survival of less than 5 years compared with 2 years in the EBPG. The general principles of the pre-transplant assessment listed above are not controversial and constitute best practice. However, the exact mechanism by which some of the individual objectives may be met remain unclear and inevitably results in an element of subjectivity.

\section{Guideline 2.2 - Tx : Pre-transplant cardiac assessment}

We suggest that there is no compelling evidence that pre-transplantation screening tests for coronary artery disease in asymptomatic patients with established renal failure is effective in preventing future cardiac events or reducing mortality after transplantation. Until better evidence emerges, screening tests may be best used to identify high-risk patients for exclusion from the transplant waiting list. (2C)

\section{Rationale}

Although age, diabetes mellitus and pre-existing coronary artery/peripheral vascular disease are factors that identify individuals at a higher risk of cardiac mortality after transplantation [3-5], it is uncertain whether revascularisation of coronary artery lesions reduces the risk of postoperative events or prolongs survival of patients before transplantation. In a prospective observational cohort study of 300 consecutive patients screened for cardiovascular disease in Glasgow prior to listing for transplantation, there was no significant survival difference between those patients referred for coronary angiography compared to those who were not, despite the higher perceived cardiovascular risk of patients undergoing invasive tests [6]. There was also no apparent survival difference between patients who underwent percutaneous coronary intervention (PCI) compared with those who underwent angiography without intervention, or those who had no angiography although the numbers were small and the rate of intervention was low. While the results of screening (including the inability to perform an exercise stress test for $>6$ minutes) were important predictors of survival, they did not lead to intervention and did little more than exclude patients from transplantation. Furthermore, trials in the nonrenal population have shown that prophylactic coronary artery revascularisation does not reduce long term all cause mortality or improve outcomes in high risk patients undergoing major non-cardiac surgery [7]. To answer the question of whether pre-transplant screening and subsequent coronary intervention improves survival in patients with established renal failure and coronary artery disease requires a large prospective multi-centre randomised study. Until then it remains uncertain whether screening and subsequent intervention in high-risk patients is effective in preventing future cardiac events or reducing mortality after transplantation [8]. When performed, screening tests may be best used to identify high-risk patients for exclusion from the transplant waiting list.

\section{Guideline $2.3-T x$ : Preparation of the renal transplant recipient}

We suggest that the use of pre-operative beta-blockers may be considered in patients at high cardiovascular 
risk undergoing renal transplantation but should be introduced at least 1 month before transplantation. Betablockers should not be discontinued abruptly perioperatively. Low dose aspirin and clopidogrel therapy are not contraindications to transplantation. (2C)

\section{Rationale}

Despite recommendations by a number of guideline committees for the use of beta-blockers in high-risk patients undergoing non-cardiac surgery to prevent peri-operative cardiovascular events, evidence of the efficacy of this approach from randomised clinical trials is limited and untested in the context of renal transplantation [9]. Recent evidence from a large randomised controlled trial (POISE) of peri-operative beta-blockers started 2-4 hours before non-cardiac surgery showed that although the primary end-point of cardiac death, non-fatal myocardial infarction or cardiac arrest was reduced in the beta-blocker group, this was at the cost of an increased incidence of total mortality and stroke [10]. The most recent meta-analysis of 33 randomised trials including over 12,000 patients, of whom over 8,000 were from POISE, has concluded that although peri-operative beta-blockers reduced the risk of nonfatal myocardial infarction (NNT 63) and myocardial ischaemia (NNT 16) there was no significant reduction in all cause mortality, cardiovascular mortality or heart failure. Indeed, their use increased the risk of bradycardia and hypotension needing treatment and increased the risk of non-fatal strokes (NNH 293) [11]. A large US cohort study in which the outcome of patients undergoing non-cardiac surgical procedures was analysed according to whether or not they received beta-blockers within the first 2 days of hospitalisation concluded that high-risk patients who received beta-blockers were significantly less likely to die in hospital. However, low risk patients receiving beta-blockers were more likely to die [12]. Evidence from the DECREASE study suggests that if pre-operative beta-blockers are used they should be introduced at least one month prior to transplantation [13]. For patients already taking a beta-blocker, therapy should be continued given the risks of sudden cessation. The recently published guideline update from the American College of Cardiology/American Heart Association provides sensible advice on preoperative beta-blocker use based on the current published evidence [14]. The guidelines state that beta-blockers titrated to heart rate and blood pressure are probably recommended for patients undergoing intermediate- or high-risk surgical procedures whose pre-operative assessment identifies coronary heart disease or high cardiac risk. To avoid peri-operative bradycardia and hypotension, it would be prudent to start beta-blockers at least one month prior to transplantation.

Aspirin has a major role in the primary and secondary prevention of myocardial infarction and reduces the severity of silent myocardial ischaemia in both stable and unstable angina. Peri-operative aspirin therapy is associated with a significant reduction in mortality in patients undergoing coronary bypass surgery and is not associated with an increased risk of bleeding or gastritis [15]. It interferes with platelet aggregation induced by thromboxane $\mathrm{A}_{2}$ but not by either thrombin or high concentrations of collagen. Therefore, clinically significant bleeding should not be made worse by peri-operative aspirin [16]. Furthermore, the use of low dose perioperative aspirin may reduce the risk of transplant renal vein thrombosis [17]. Patients taking clopidogrel may be more likely to bleed peri-operatively and require blood transfusions but this should not be considered a contra-indication to renal transplantation. The use of platelet infusions may reduce this risk $[18,19]$.

\section{Guideline 2.4 - Tx : Preparation of the renal transplant recipient}

We recommend that patients should be strongly encouraged to stop smoking before and after transplantation. Formal smoking cessation programmes should be offered and accessed in primary care. (1A)

\section{Audit measure}

The proportion of patients who smoke (or have given up within the last year)

(a) while listed for transplantation

(b) one year after renal transplantation

\section{Rationale}

Cigarette smoking increases the risk of cancer and cardiovascular disease in the general population. Only a few studies have examined the effect of cigarette smoking on renal transplantation but all show an association with reduced patient and graft survival. In one study of patients with a functioning graft at least one year after transplantation, cigarette smoking correlated with reduced patient survival and the magnitude was quantitatively similar to that conferred by diabetes [20]. In a larger single centre North American study, smoking more than 25 pack-years at the time of transplantation 
(compared to smoking less than 25 pack-years or never having smoked) was associated with a $30 \%$ higher risk of graft failure after correcting for multiple known risk factors [21]. The increase in graft failure was largely due to an increase in deaths. Stopping smoking more than 5 years before transplantation reduced the relative risk of graft failure by $34 \%$. The relative risks of major cardiovascular disease events and invasive malignancies were significantly increased in smokers. Similar results have been observed in another study in which pre-transplant smoking was associated with reduced transplant and death-censored graft survival, although death-censored graft survival was significantly higher in patients who stopped smoking before transplant evaluation [22]. Evidence suggests that with appropriate interventions, many patients can stop smoking [23, 24].

\section{Guideline $2.5-T x$ : Preparation of the renal transplant recipient}

We suggest that obese patients (BMI $>30 \mathrm{~kg} / \mathrm{m}^{2}$ ) present technical difficulties and are at increased risk of peri-operative complications. They should be screened rigorously for cardiovascular disease and each case considered individually. Although obesity is not an absolute contra-indication to transplantation, individuals with a BMI $>40 \mathrm{~kg} / \mathrm{m}^{2}$ are less likely to benefit. (2B)

\section{Audit measure}

(a) The proportion of obese patients (BMI $>30 \mathrm{~kg} /$ $\mathrm{m}^{2}$ ) on the transplant waiting list who have had a cardiac assessment

(b) The number of patients with BMI $>40 \mathrm{~kg} / \mathrm{m}^{2}$ who are on the transplant waiting list and the reason for their inclusion

\section{Rationale}

Body mass index (BMI) is the most widely used marker of obesity despite its limitations. According to the WHO classification a BMI of $30-34.9 \mathrm{~kg} / \mathrm{m}^{2}$ is defined as obese class I (mild), $35-39.9 \mathrm{~kg} / \mathrm{m}^{2}$ as obese class II (moderate) and $>40 \mathrm{~kg} / \mathrm{m}^{2}$ as obese class III (morbid). The impact of obesity on outcome after renal transplantation has been controversial. For obese patients overall, registry data have demonstrated a significant survival advantage for recipients of both deceased and living donor transplantation compared with remaining on dialysis [25]. However, recipients of deceased donor transplants with a BMI $>41 \mathrm{~kg} / \mathrm{m}^{2}$ had no survival benefit. Some single centre studies have shown that wound infection, delayed graft function and weight gain are more common complications in moderately and morbidly obese transplant recipients although patient and graft survival are unchanged [2628]. In a small paired kidney analysis of 28 pairs, obesity defined as a BMI $>30 \mathrm{~kg} / \mathrm{m}^{2}$ was associated with decreased graft survival at 5 years [29]. In another study in which patients were rigorously screened (and excluded) for cardiovascular disease before acceptance for transplantation, 5 year patient and graft survival were no different in the obese (BMI $>30 \mathrm{~kg} / \mathrm{m}^{2}$ ) group although wound breakdown was commoner [30]. A recent analysis of 27,377 patients from the UNOS database showed that compared with normal weight patients, a BMI $>35 \mathrm{~kg} / \mathrm{m}^{2}$ was independently associated with an increased risk of delayed graft function, prolonged hospitalisation, acute rejection and decreased overall graft survival, although a high proportion of such individuals were African Americans and had diabetes mellitus [31].

\section{Guideline 2.6 - Tx : Preparation of the renal transplant recipient}

We recommend that all potential transplant recipients should be tested for prior exposure to viral infections including: cytomegalovirus (CMV), Epstein-Barr virus (EBV), varicella zoster virus (VZV), hepatitis B and C and human immunodeficiency virus (HIV). Immunisation should be offered to all hepatitis B (if not already immunised) and VZ virus antibody negative patients before transplantation. Patients otherwise suitable for renal transplantation with evidence of chronic hepatitis $\mathrm{B}$ and/or C or HIV infection should be managed according to British Transplantation Society and European Best Practice Guidelines prior to transplantation. (1A)

\section{Audit measure}

(a) The proportion of patients on the transplant waiting list whose viral status is known for CMV, EBV, VZV, hepatitis B and C and HIV

(b) The proportion of VZV and $\mathrm{HBc}$ antibody negative patients on the transplant waiting list who have been immunised against these viruses

\section{Rationale}

It is important to know if potential transplant recipients have had exposure to certain viruses, notably Epstein-Barr virus (EBV), cytomegalovirus (CMV) and varicella zoster virus $(\mathrm{HZV})$. EBV negative recipients of an EBV positive transplant have a seven-fold increased risk of post-transplant lympho-proliferative disorder 
(PTLD) [32]. Knowledge of recipient CMV serology at transplantation is essential to guide antiviral prophylactic strategies [33].

Potential recipients who are hepatitis B surface antigen positive will require assessment by a hepatologist with liver biopsy if circulating viral DNA is present before placement on the waiting list [34]. Active viral replication, chronic active hepatitis or cirrhosis has a poor prognosis if untreated before transplantation [35]. In hepatitis $C$, survival post-transplantation is increased over remaining on dialysis [36]. It is recommended that the potential transplant recipient has a liver biopsy to assess liver damage and consideration of treatment before transplantation [37].

The advent of highly active antiviral therapy has revolutionised the prognosis of HIV, and early experience suggests similar early graft and patient survival rates between HIV - positive and negative renal transplant recipients [38]. Guidelines for the management of potential kidney transplant recipients with HIV infection should be followed [39].

Guideline 2.7 - Tx : Evaluation and selection of the renal transplant recipient

We recommend that in potential recipients with previous malignancy (excluding non-melanoma skin cancer), renal transplantation should only be considered if there is no evidence of persistent cancer. It is recommended that the waiting time between successful tumour treatment/remission and transplantation be at least 2 years. For certain malignancies the waiting time may need to be extended to more than 5 years. The Israel Penn International Transplant Tumour Registry should be consulted for tumour specific advice (Www. ipittr.uc.edu/Home.cfm). (1A)

\section{Rationale}

The risk of several forms of malignancy is markedly increased after transplantation [40], due in part to alteration of immune surveillance mechanisms with maintenance immunosuppression. Patients with successfully treated cancer can be considered for renal transplantation however it is important to estimate the risk of cancer relapse before placement on the transplant waiting list. Relapse of solid organ tumours is dependent upon tumour type and time interval between treatment and transplantation. Overall 53\% of recurrences occur in patients transplanted within 2 years of cancer treatment, falling to $34 \%$ if the interval between treatment and transplantation is $2-5$ years and $13 \%$ if the interval is more than 5 years [41]. The risk of recurrence is very low for non-melanoma skin cancer and in-situ carcinoma of the cervix or bladder such that no delay in placement on the waiting list is required. The risk of recurrent colorectal cancer, melanoma, and breast cancer is higher and the disease-free interval may need to be at least 5 years before transplantation depending on circumstances [41]. Liaison with an oncologist is advised.

Although there is evidence that dialysis patients have an increased incidence of cancer compared with the general population [42], currently there is no evidence that dialysis patients on the transplant waiting list should have increased cancer surveillance strategies over that recommended for the general population [43]. Previous post-transplant lymphoproliferative disease (PTLD) is not a contraindication to re-transplantation.

\section{Guideline 2.8 - Tx : Evaluation and selection of the renal transplant recipient}

We recommend that patients who are at risk of developing recurrence of original renal disease should be managed according to the European Best Practice Guidelines (EBPG) and the UK Guidelines for Living Donor Kidney Transplantation. (not graded)

\section{Rationale}

Recurrent disease accounts for approximately 5\% of all allograft loss [44]; primary focal segmental glomerulosclerosis, IgA nephropathy, mesangiocapillary glomerulonephritis type II and diabetic nephropathy are the commonest causes. Pre-transplantation counselling should include the potential risk of recurrent disease in appropriate patients. In rare circumstances transplantation may be contraindicated because of the very high risk of recurrent disease for example in recipients who have lost their first allograft early from recurrent disease $[45,46]$.

\section{Guideline 2.9-Tx: Screening investigations in the renal transplant recipient}

We suggest that there is no evidence that asymptomatic potential transplant recipients require screening for diverticular disease, peptic ulceration or gall bladder stones. (2C)

\section{Rationale}

Colonic perforation due to diverticular disease is rare with modern immunosuppressive regimes which use low dose corticosteroids. In a retrospective study in which all 
transplant candidates aged more than 50 years underwent screening, none of the patients with significant diverticular disease had symptomatic disease posttransplantation [47]. Patients with clinically significant disease should be assessed and managed according to standard practice. Peptic ulceration is now rarely a serious problem and there is a low morbidity rate even in patients with past peptic ulcer disease [48]. Most transplant centres ignore incidental cholelithiasis and there is no published evidence from the recent era to support a role for screening and intervention before transplantation.

\section{References}

$\checkmark 1$ Ravanan R, Udayaraj U, Ansell D et al. Variation between centres in access to renal transplantation in the UK; longitudinal cohort study. BMJ 2010;341:c3451

2 www.bts.org.uk

$\$ 3$ Le A., Wilson R, Douek K et al. Prospective risk stratification in renal transplant candidates for cardiac death. Am J Kidney Dis 1994;24(1): 65-71

-4 Humar A, Kerr AR, Ramcharan Tet al. Peri-operative cardiac morbidity in kidney transplant recipients: incidence and risk factors. Clin Transplant 2001;15:154-158

5 Lentine K.L., Brennan DC, Schnitzler MA. Incidence and predictors of myocardial infarction after kidney transplantation. J Am Soc Nephrol 2005;16(2):496-506

6 Patel RK, Mark PB, Johnston N et al. Prognostic value of cardiovascular screening in potential renal transplant recipients: a single-centre prospective observational study. Am J Transplant 2008;8:1673-1834

7 McFalls EO, Ward HB, Moritz TE et al. Coronary-artery revascularization before elective major vascular surgery. N Engl J Med 2004;351(27): 2795-2804

8 Kasiske BL, Malik MA, Herzog CA. Risk-stratified screening for ischemic heart disease in kidney transplant candidates. Transplantation 2005;80(6):815-820

$\checkmark 9$ Poldermans D, Bax JJ, Boersma E et al. Guidelines for pre-operative cardiac risk assessment and perioperative cardiac management in non-cardiac surgery: the task force for preoperative cardiac risk assessment and perioperative cardiac management in non-cardiac surgery of the European Society of Cardiology (ESC) and endorsed by the European Society of Anaesthesiology (ESA). Eur Heart J 2009;30:2769-2812

10 POISE Study Group, Devereaux PJ, Yang H, Yusuf S et al. Effect of extended-release metoprolol succinate in patients undergoing noncardiac surgery (POISE trial): a randomised controlled trial. Lancet 2008;371:1839-1847

11 Bangalore S, Wetterslev J, Pranesh S et al. Perioperative $\beta$ blockers in patients having non-cardiac surgery: a meta-analysis. Lancet 2008;372: 1962-1976

$\checkmark 12$ Lindenauer PK., Pekow P, Wang K et al. Perioperative beta-blocker therapy and mortality after major non-cardiac surgery. N Engl J Med 2005;353(4):349-361

13 Poldermans D, Boersma E, Bax JJ et al. The effect of bisoprolol on perioperative mortality and myocardial infarction in high-risk patients undergoing vascular surgery. N Engl J Med 1999;34:1789-1795

$\checkmark 14$ Fleischmann KE, Beckman JA, Buller CE et al. ACCF/AHA focused update on perioperative beta blockade. J Am Coll Cardiol 2009;54: 2102-2128

15 Mangano DT and the Multicenter Study of Peri-operative Ischemia Research Group. Aspirin and mortality from coronary bypass surgery. N Engl J Med 2002;347(17):1309-1317

16 Auerbach A, Goldman L. Assessing and reducing the cardiac risk of non-cardiac surgery. Circulation 2006;113(10):1361-1376

17 Robertson AJ, Nargund V, Gray DW, Morris PJ. Low dose aspirin as prophylaxis against renal-vein thrombosis in renal-transplant recipients. Nephrol Dial Transplant 2000;15(11):1865-1881
18 Ozao-Choy J, Tammaro Y, Fradis M et al. Clopidogrel and bleeding after general surgery procedures. Am Surg 2008;74:721-725

19 Bry W, Peddi V, Katznelson S et al. Kidney transplantation on Plavix: Feasible or foolhardy? Am J Transplant 2008;8(Suppl 2):516

20 Cosio FG, Falkenhain ME, Pesavento TE et al. Patient survival after renal transplantation: II. The impact of smoking. Clin Transplant 1999;13(4):336-341

21 Kasiske B and Klinger D. Cigarette smoking in renal transplant recipients. J Am Med Assoc 2000;11:753-759

22 Sung RS, Althoen M, Howell TA et al. Excess risk of renal allograft loss associated with cigarette smoking. Transplantation 2001;71(12): 1752-1757

23 Silagy C, Mant D, Fowler G, Lodge M. Meta-analysis on efficacy of nicotine replacement therapies in smoking cessation. Lancet 1994;343: 139-142

24 Hughes JR, Goldstein MG, Hurt RD, Shiffman S. Recent advances in the pharmacotherapy of smoking. J Am Med Assoc 1999;281:72-76

25 Glanton CW, Kao TC, Cruess D et al. Impact of renal transplantation on survival in end-stage renal disease patients with elevated body mass index. Kidney Int 2003;63(2):647-653

26 Drafts HH, Anjum MR, Wynn JJ et al. The impact of pre-transplant obesity on renal transplant outcomes. Clin Transplant 1997;11:493-496

27 Howard RJ, Thai VB, Patton PR et al. Obese kidney transplant recipients have good outcomes. Transplant Proc 2001;33:3420-3421

28 Lynch RL, Ranney DN, Shijie C et al. Obesity, surgical site infection and outcome following renal transplantation. Ann Surgery 2009;250: 1014-1020

29 Yamamoto S, Hanley E, Hahn AB et al. The impact of obesity in renal transplantation: an analysis of paired cadaver kidneys. Clin Transplant 2002;16(4):252-256

30 Johnson DW, Isbel NM, Brown AM et al. The effect of obesity on renal transplant outcomes. Transplantation 2002;74(5):675-681

31 Gore JL, Pham PT, Danovitch GM et al. Obesity and outcome following renal transplantation. Am J Transplant 2006;6:357-363

-32 Shahinian VB, Muirhead N, Jevnikar AM et al. Epstein-Barr virus seronegativity is a risk factor for late onset post-transplant lymphoproliferative disorder in adult renal allograft recipients. Transplantation 2003;75:851-856

33 Newstead C, Griffiths PD, O’Grady JG, Parameshwar JK. Guidelines for the prevention and management of cytomegalovirus after solid organ transplantation. 2nd Edition. British Transplantation Society 2004. ISBN 0-9542221-3-X

34 European Best Practice Guidelines (EBPG). Nephrol Dial Transplant 2000;15(7):9-11

35 Fornairon S, Pol S, Legendre C et al. The long-term virologic and pathologic impact of renal transplantation on chronic hepatitis $\mathrm{B}$ virus infection. Transplantation 1996;27:297-299

36 Pereira BJ, Natov SN, Bouthot BA et al. Effects of hepatitis C infection and renal transplantation on survival in end-stage renal disease. Kidney Int 1998;53:1374-1381

37 European Best Practice Guidelines (EBPG). Nephrol Dial Transplant 2000;15(7):7-9 
38 Abbott KC, Swanson SJ, Agodoa LY, Kimmel PL. Human immunodeficiency virus infection and kidney transplantation in the era of highly active antiretroviral therapy and modern immunosuppression. J Am Soc Nephrol 2004;15:1633-1639

39 Guidelines for Kidney Transplantation in Patients with HIV Disease 2005 www.bts.org.uk/standards

40 Agraharkar ML, Cinclair RD, Kuo YF et al. Risk of malignancy with long-term immunosuppression in renal transplant recipients. Kidney Int 2004;66:383-389

41 Penn I. The effect of immunosuppression on pre-existing cancers. Transplantation 1993;55:742-747

42 Maisonneuvre P, Agodoa L, Gellert R et al. Cancer in patients on dialysis for end-stage renal disease: An international collaborative study. Lancet 1999;10:93-99

43 Kiberd BA, Keough-Ryan T, Clase CM. Screening for prostate, breast and colorectal cancer in renal transplant recipients. Am J Transplant 2003;3:619-625

\section{Acknowledgements}

The above guidelines on the assessment of the potential renal transplant recipient have been endorsed by the British Transplantation Society. We are grateful to all those who have commented on draft versions of these guidelines in particular Dr Peter Andrews and Mr Keith Rigg.

Dr Chris Dudley has had financial support to attend educational meetings from Shire.
44 Chadban S. Glomerulonephritis recurrence in the renal graft. J Am Soc Nephrol. 2001;12(2):394-402

45 European Best Practice Guidelines (EBPG). Nephrol Dial Transplant 2000;15(7):11-20

46 http://www.bts.org.uk/transplantation/standards-and-guidelines

47 McCune TR, Nylander WA, van Buren DH et al. Colonic screening prior to renal transplantation and its impact on post-transplant colonic complications Clin Transplant. 1992;6(2):91-96

48 Troppman C, Papalois BE, Chiou A et al. Incidence, complications, treatment, and outcome of ulcers of the upper gastrointestinal tract after renal transplantation during the cyclosporine era. J Am Coll Surg 1995;180:433-443
Dr Paul Harden has participated in multicentre clinical research studies supported by Astellas, Novartis and Pfizer and has received sponsorship to attend educational meetings from Astellas, Novartis, Pfizer and Roche. 